\title{
An Insight into the Periodontal Restorative Interrelationship
}

\author{
Brahmandabheri Nithisha $^{1}$, Chitturi Ravi Kumar ${ }^{2}$, DuggineniChalapathi Rao ${ }^{3}$, Machha \\ Sujesh $^{4}$, D. Sreenivasulu ${ }^{5}$ \\ Department of Prosthodontics, Mamata Dental College, Khammam, Telangana, India
}

Email for correspondence: nithisha.bheri@gmail.com

\begin{abstract}
The interdisciplinary approach has been a standard for a profound dental treatment. Periodontics and prosthodontics, among all disciplines of dentistry, have the most harmonious and indissoluble relationship in a melange of perspectives. A prosthesis can be supporting or disrupting relying on the anticipation given to it. The finest environment for the prosthesis is obtained by means of pretreatment consultation between the periodontist and the prosthodontist. To facilitate this partnership, the prosthodontist should not only accept the periodontal implications of various procedures but should also be knowledgeable about the various factors that help in maintaining the periodontal tissues surrounding the prosthodontic restorations. The present article addresses the interrelationship between significance of health of periodontal tissues during and after dental restorative procedures including the major considerations, namely biologic, esthetic, occlusal, and special consideration to coordinate and interface these perspectives and provides the best quality of care to the patient.
\end{abstract}

Key words: Biologic width, gingival margin, periodontics, prosthodontics, restorative

\section{INTRODUCTION}

The relationship between periodontal health and the restoration of teeth is intimate and inseparable. ${ }^{[1]}$ For the long-term survival of prostheses, it is mandatory that periodontium should remain healthy, prostheses should be in harmony with their surrounding periodontal tissues and prostheses should promote health of the periodontium and not to destroy it. ${ }^{[2,3]}$

The considerations for successful and harmonious periodontal-prosthetic interrelationship can be divided under the following headings:

a. Biologic considerations.

b. Esthetic considerations.

c. Occlusal considerations.

d. Special considerations.

\begin{tabular}{|l|l|}
\hline Quick Response Code & Article Info: \\
\hline doi: 10.5866/2018.10.10041 & $\begin{array}{l}\text { Received: } 29-12-2017 \\
\text { Revised: } 26-01-2018 \\
\text { Accepted: } 02-02-2018 \\
\text { Available Online: } 15-04-2018,2018 \text { (www. } \\
\text { nacd.in)@ NAD, 2018 - All rights reserved }\end{array}$ \\
\hline
\end{tabular}

\section{Biologic considerations}

Margin placement and biologic width

- Evaluation of biologic width.

- Correction of biologic width violations.

- Margin placement guidelines.

Effective clinical procedures and margin placement

- Tissue retraction.

- Provisional restorations.

- Marginal fit.

- Crown contour.

- Subgingival debris.

- Hypersensitivity to dental materials.

\section{Biologic width and margin placement}

Restorative clinician must understand the role of the biologic width in preserving healthy gingival tissues and controlling the gingival form around the restorations. Application of this information is helpful in positioning the restorative margins especially in the esthetic zone, where a primary treatment goal is to mask the junction of the margin with the tooth.

The dimension of dentogingival complex, called "biologic width," is present around the natural teeth 
in the form of a protective cuff-like barrier. It has a tendency of self-restoration and adapts dynamically. This biologic width includes junctional epithelium and connective tissue attachments. The epithelial and connective tissue components are separated by an average distance of $0.97 \mathrm{~mm}$ and $1.07 \mathrm{~mm}$, respectively, although epithelial attachment has compelling dimensions, differing in individuals [Figure 1]. The preservation of periodontal health is dependent on the biologic width. During the establishment of the position of restorative margins in relation to the periodontal attachment, ideally patients existing sulcular depth should be used as a guideline to evaluate the biologic width specification for patient. ${ }^{[4,5]}$

\section{Sulcus depth - restorative margins}

\section{Guidelines}

1. Place the restoration margins $0.5 \mathrm{~mm}$ below the gingival tissue crest if the sulcus probes $1.5 \mathrm{~mm}$ or less.

2. Place the margin half the depth of the sulcus below the tissue rest if the sulcus probes more than $1.5 \mathrm{~mm}$

3. If sulcus more than $2 \mathrm{~mm}$ is observed mainly at the buccal aspect of the tooth, consider if gingivectomy procedure can be performed for teeth lengthening and create sulcus of $1.5 \mathrm{~mm} \cdot{ }^{[4]}$

\section{Evaluation of biologic width}

Biologic width can be evaluated by means of clinical examination, radiographs, and probing depth. Clinically, tissue discomfort may be observed when the restoration margin levels are being assessed with a probe. Probing depth may vary

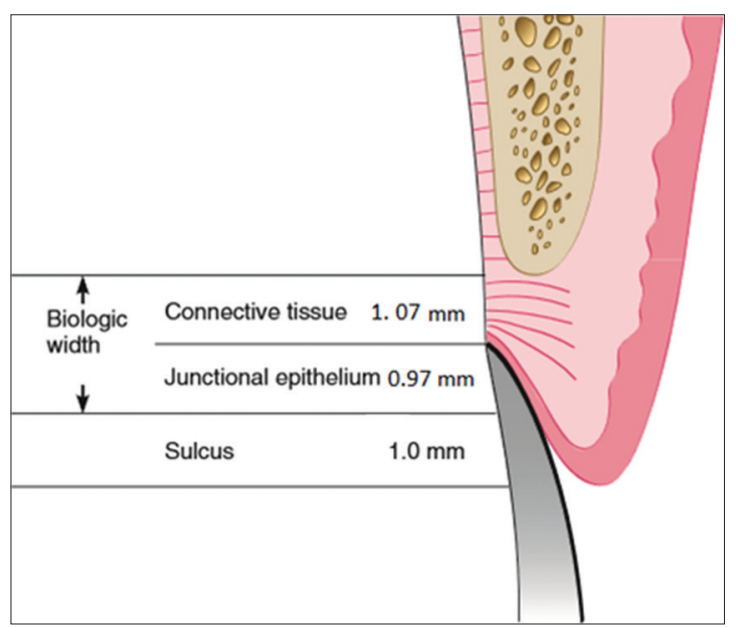

Figure 1: Picture showing average human biological width, epithelium: $0.97 \mathrm{~mm}$, and connective tissue: $1.07 \mathrm{~mm}$ from individual to individual at locations around the teeth. Probing is under anesthesia referred as sounding to bone. Radiographs are also of value in assessing biologic width, except that only interproximal biologic width violations can be ascertained. Combination of clinical examination, probing coupled with radiographs will be better in evaluating biologic width.

\section{Biologic width violations}

Overhanging restorations violating biologic width area can result in gingival inflammation, loss of periodontal tissue attachment, and unpredictable bone loss. Clinically, it can be detected as gingival bleeding, periodontal pocket formation, and gingival recession. ${ }^{[5]}$

\section{Correcting biologic width violations}

Biologic width violation is modified either by separating the bone surgically away from vicinity to the margins of restorations or by orthodontic approach of tooth extrusion and thereby shifting of the margin away from the bone. Gingival recession following the removal of bone is the most probable risk factor. After the interproximal bone is removed, high possibility of papillary recession with the formation of unesthetic triangle of space is noticed at the interproximal contacts inferiorly. Orthodontic extrusion of the teeth is intended when the biologic width violation involves interproximal side or across the facial surface. ${ }^{[5-9]}$

\section{Margin placement}

A clinician is presented with three choices for margin placement: Supragingival, equigingival, and subgingival. ${ }^{[2]}$

\section{Supragingival margins}

- Least impact on periodontium.

- Chosen for non-esthetic areas due to marked contrast in color and opacity traditional restorative materials against the tooth margins.

\section{Equigingival margins}

- Well tolerated.

- Can be used in esthetic areas as the prosthetic margin can be merged and polished to provide smooth interface at the gingival margin.

Both supra and equigingival margins are acceptable from periodontal perspective as they are easily accessible for plaque removal.

The greatest biologic hazard occurs when placing subgingival margins. ${ }^{[6,7]}$ In this type of margin, there 
is higher risk of biologic width invasion, increasing further periodontal destruction.

\section{Gingival retraction and impressions}

a. A momentary trauma is seen in the region of junctional epithelium and connective tissue of gingival sulcus with all retraction methods. Retraction cord: It creates minimal gingival recession and also preserves the sulcular tissues while tooth preparation. If the retraction cord is used with negligence or when inadequate attached gingiva is present, gingival fiber injury takes place. This leads to the impression material infuse into the gingival connective tissue and bone generating foreign body reaction.

b. Electrosurgery: This procedure comes with a few constraints. Electrosurgery when done correctly, the cellular healing is comparable to a scalpel cut. Cutting electrode tips with controlled depth are used to prevent bone trauma, but the gingival fibers injure if the tip is not adequately angled in the sulcus. To enhance healing, Oringer's solution or surgical pack is used.

Electrosurgery is contraindicated in patients with thin covering of gingiva and alveolar bone over the root as gingival recession can occur by the loss of tissue from the internal or crevicular surface. Retraction cords are preferred in these patients to retract the gingiva. Apart from these, numerous methods of gingival displacement including mechanical and surgical, chemomechanical, and surgical methods are available. ${ }^{[10,11]}$ As a substitute to displacement cord methods, cordless techniques are introduced with the advantages of time saving, ease of use, low-pressure generation, and high patient comfort along with being less invasive.

\section{Guidelines}

1. When the sulcus depth is $1.5 \mathrm{~mm}$ or less, the cord is to be positioned in the sulcus at the height of final margin, i.e. $0.5 \mathrm{~mm}$ lower to the previously prepared margins. As the interproximal sulcus is $2.5-3 \mathrm{~mm}$ in depth, the cord is to be placed $1-1.5 \mathrm{~mm}$ below the tissue height [Figure 2]. ${ }^{[4]}$

2. In the case of deeper sulcus, two cords with larger diameter are used for the deflection of the tissue before the extension of the margins apically. For the identification of final margin position, the top of the second cord is positioned at the proper distance inferior to previously prepared margin that was at the gingival crest level. The margin is brought in level with the top of the second cord [Figure 3]. During the impression making, the third cord is placed in the preparation [Figure 4]. Electrosurgery is indicated in the patients with a deep sulcus where margin may be $1.5-2.0 \mathrm{~mm}$ below the tissue crest to remove the overhanging tissue [Figure 5]. ${ }^{[4]}$

\section{The provisional restoration}

To maintain the health and position of the gingival tissues till the final restorations are delivered, it is necessary that the marginal fit, crown contour, and surface finish line of the interim restorations are to be appropriate. Inaccurate

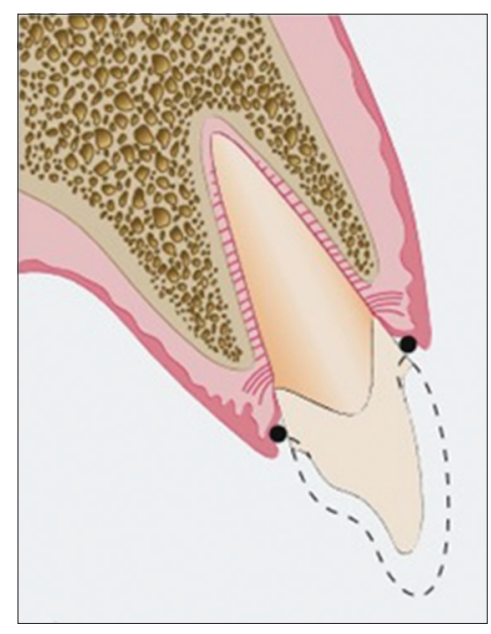

Figure 2: Picture showing placement of single cord $0.5 \mathrm{~mm}$ below the previous margin making

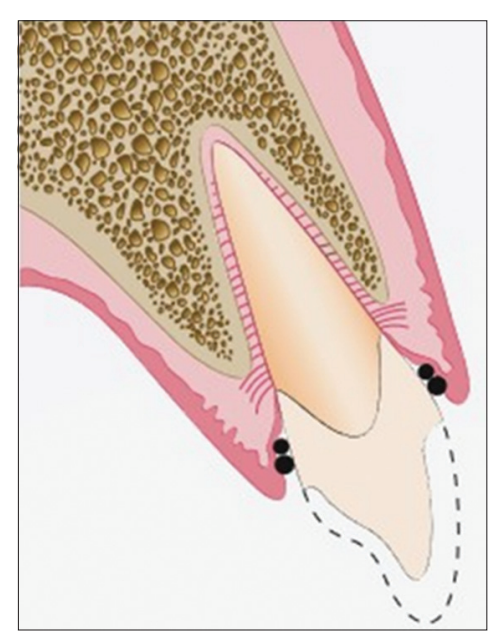

Figure 3: Picture showing placement of the second cord inferior to the prepared margin at crest level 


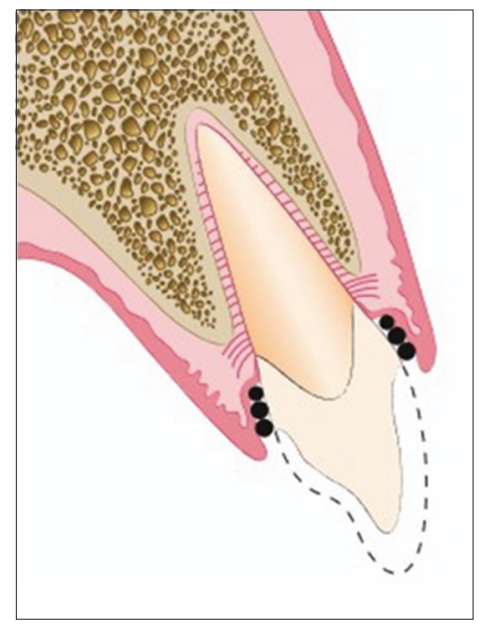

Figure 4: Picture showing placement of the third cord for impression making

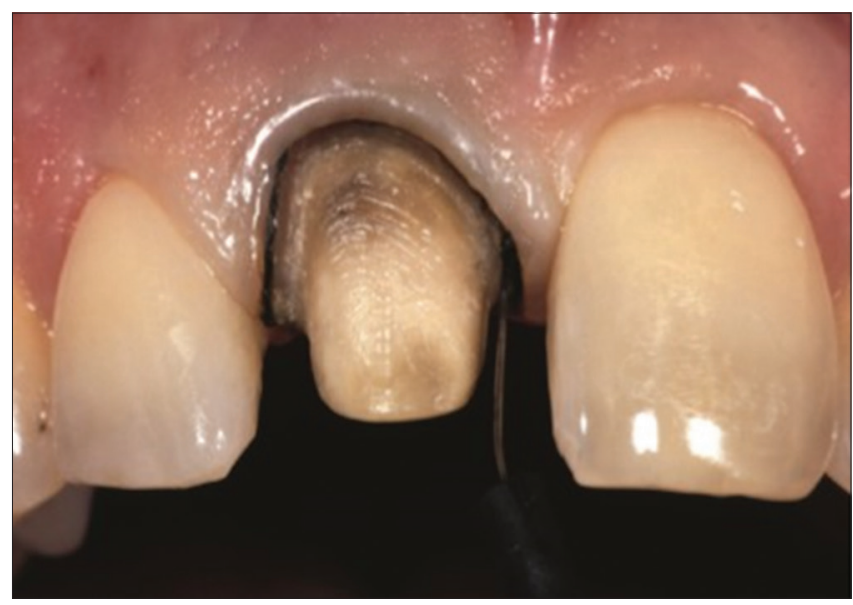

Figure 5: Clinical picture showing electrosurgery in deep sulcus to remove overhanging tissues

provisional restorations with poor adaptation at the margins being over or under contoured with rough or porous surfaces result in inflammation, overgrowth, or recession of gingival tissues. ${ }^{[12]}$

\section{Marginal fit}

Inflammatory response in the periodontium is directly proportional to gap at the tooth-restoration interface. Ideally, there should not be any gap at the tooth restoration interface. Studies have suggested that gap of $50 \mathrm{um}$ is clinically acceptable.

\section{Crown contour}

Restoration contour is extremely important to the maintenance of periodontal health. Properly designed contours provide access for hygiene, have the fullness to create the desired gingival form, and have a pleasing visual tooth contour in esthetic areas. There seems to be an association between over contouring and gingival inflammation according to evidence from human and animal studies, although no periodontal effect is noticed with under contouring. Inadequate tooth preparation by the dentist is the most common reason for the production of over contoured restorations, resulting from the fabrication of bulky restoration to provide space for the restorative material. ${ }^{[13,14]}$

\section{Theory of access for oral hygiene}

According to this theory, plaque is the chief etiologic factor in caries and gingivitis. Hence, plaque removal should not be hampered but facilitated by contouring of crown. ${ }^{[15]}$

\section{Guidelines to contour the crowns}

1. Facial and palatal contouring-Flat not rounded. Facial and palatal surfaces are the primary plaque retentive areas, especially at the infrabulge of the tooth. Reduction in plaque retention is noticed by the reducing the infrabulge area.

2. Unobstructed embrasures - The interproximal areas should allow effortless and easy access for plaque control. Over contouring of the embrasures should be avoided as it reduces intended area for the gingival papilla.

3. Contact location - With maxillary first and second molars as exception, all the contacts are to be designed and constructed incisally or occlusally and buccally in relation to the central fossa. This measure establishes a large lingual embrasure space to maintain the optimum health of lingual papilla.

4. Furcation involvement - Based on the approach of discarding plaque traps, the furcation exposed due to loss of periodontal attachments should be fluted or barreled out.

\section{Subgingival debris}

Leaving the debris below the tissue during restorative procedures creates an adverse periodontal response. The cause can be retraction cord, impression material, provisional material, or either temporary or permanent luting agents. Care must be taken not to any residue by examination and gentle passage of an explorer around the restorations.

Hypersensitivity to dental materials Inflammatory gingival responses have been 
reported related to the use of non-precious alloys, autopolymerizing resins along with roughness used to fabricate provisional and definitive restorations.

\section{Esthetic considerations}

\section{Interproximal embrasure form}

The ideal interproximal embrasure should house the gingival papilla without impinging on it and also extend the tooth contact interproximally to the top of the papilla so that no excess space exists to trap food and appear esthetically pleasing.

\section{The gingival embrasure}

From a periodontal viewpoint, the gingival embrasure is the most significant.

Periodontal diseases cause tissue destruction, which reduces the level of alveolar bone, increases the size of the gingival embrasure, and creates an open interdental space. Restorations may be constructed to preserve the morphologic features of the crown and root and retain the enlarged embrasure space or when esthetic situations dictate, the teeth may be reshaped by the restorations so that the gingival embrasures are relocated close to the new level of the gingiva.

\section{Pontic design}

The following are the ideal characteristics of a pontic:

1. Should provide satisfactory esthetics.

2. Should help to maintain sufficient occlusal relationship with the abutment teeth.

3. Masticatory performance should be reestablished.

4. Should be designed to diminish dental plaque and food debris accumulation.

5. Should provide acceptable embrasures for easy passage of food.

The patient's oral hygiene plays a crucial role in maintaining the health of the tissues around the fixed prosthesis. Very little difference occurs with the pontic material and the pontic design. These are necessary only to enable the patients to keep the area clean.

Glazed and unglazed porcelain, polished gold, and polished acrylic resin are subjected to same degree of plaque accumulation. Pontics follow the same principles of crown contour but with increased concern regarding the tissue contours toward the tissue.

In the mandibular posterior region, esthetics is not a major consideration, so the spheroidal pontic is the design of choice because of its contour.
In the maxillary posterior area, the modified ridge lap satisfies both esthetics and hygiene.

Mandibular anterior area also requires a ridge lap design. When using a spheroidal design, the pontic contacts without pressure the tip of the ridge or the buccal surface.

When there is excessive bone loss and the rigidity of the connector is suitable (non-esthetic posterior areas), the pontic is not required to touch the ridge. There should be at least $3 \mathrm{~mm}$ of space so that the patient can maintain hygiene. ${ }^{[16]}$

\section{Occlusal considerations}

The effect of occlusal forces on the periodontium is influenced by their severity, direction, duration, and frequency. When severity increases, the periodontal fibers thicken and increase with the alveolar bone becoming denser.

Occlusal therapy should be performed as a part of periodontal treatment - whenever there is a functional indication for it.

a. Adiagnosis of TFO fully justifies occlusal therapy.

b. When malocclusion interferes with achievement of stable intermaxillary relationship, for example, migrating teeth, diastemas, and flaring of anterior teeth.

c. Bruxism may require treatment since it is the basis for every type of dysfunctional manifestation and often is the first evidence of lack of adaptation to occlusion.

Occlusal therapy is also indicated when missing teeth need to be replaced or food impaction needs to be corrected. Occlusal therapy should not be initiated unless there is evidence to indicate that the system is no longer adapting to the occlusal scheme of the individual.

\section{Occlusal adjustment}

1. Removing occlusal prematurities in centric relation and centric occlusion. A "long-centric" or "freedom in centric" when cusp tips contact horizontal stops in the fossae.

2. Eliminating balancing interferences which will allow the mandible to move freely laterally and protrusively.

3. Adjusting working contacts in lateral movements and anterior contacts in protrusion. Depending on the occlusal pattern of the individual, no single tooth should be overloaded during excursions with either group function or a cuspid protected occlusion. ${ }^{[1,8,13]}$ 


\section{Special considerations}

Restoration of root resected teeth-Root resection may be advised in multirooted teeth with furcation involvements. Restorations must be provided with appropriate contours for hygiene access.

Gingival areas may be fluted into the resected tooth to allow for ease of cleaning. Complete coverage of root resected teeth is recommended, especially over resection area. ${ }^{[2]}$

\section{Splinting}

Splinting refers to any joining together of two or more teeth for stabilization.

Splinting has three purposes as follows:

1. To protect loose teeth from injury during stabilization in a favorable occlusal relationship.

2. To distribute occlusal forces for teeth weakened by loss of periodontal support.

3. To prevent a natural tooth from migrating.

The number of teeth required to stabilize a loose tooth depends on:

a. Degree and direction of mobility.

b. The remaining bone.

c. The location of the mobile tooth.

d. Whether the tooth is to be used as an abutment tooth.

\section{Splinting methods}

It may be classified as:

1. Temporary or reversible.

2. Provisional.

3. Permanent.

Preprosthetic periodontal surgeries include mucogingival surgeries, crown lengthening procedures, and osseous recontouring procedures. ${ }^{[17]}$

\section{CONCLUSION}

Creating a physiologic periodontal climate and maintaining periodontal health has been a major objective in the treatment of restorative dentistry. Since this common goal is shared by both periodontist and the prosthodontist, communication throughout the treatment planning, procedures, and maintenance is an absolute requirement.

\section{REFERENCES}

1. Yung-Ting H, Huang NC, Wang HL. Relationship between periodontics and prosthodontics: The two-way street. J Prostho Implant 2015;4:4-11.

2. Sood S, Gupta S. Periodontal-restorative interactions: A review. Ind J Clin Prac 2013;23:707-3.

3. Padbury A Jr., Eber R, Wang HL. Interactions between the gingiva and the margin of restorations. J Clin Periodontol 2003;30:379-85.

4. SpearFM,CooneyJP.RestorativeinterRelationships,Carranza's Clinical Periodontology. $11^{\text {th }}$ ed. Philadelphia, PA: Saunders; 2011. p. 989-1007.

5. Vivekgovila S, Sharma M. Smitagovila: Periodontal restorative inter-relationship: A review. J Applied Dent Med Sci 2015;1:143-9

6. Valderhaug J. Periodontal conditions and carious lesions following the insertion of fixed prostheses: A 10-year followup study. Int Dent J 1980;30:296-304.

7. Valderhaug J. A 15-year clinical evaluation of fixed prosthodontics. Acta Odontol Scand 1991;49:35-40.

8. Muddugangadhar BC, Siddhi T, Suchismita D. Prosthoperio-restorative interrelationship. J Adv Dent Res 2011;2:6-12.

9. Ingber JS: Forced eruption. II. A method of treating non restorable teeth periodontal and restorative considerations. J Periodontol 1995;47:203.

10. Donovan TE, Gandara BK, Nemetz H. Review and survey of medicaments used with gingival retraction cords. J Prosthet Dent 1985;53:525-31.

11. Feng J, Aboyoussef H, Weiner S, Singh S, Jandinski J. The effect of gingival retraction procedures on periodontal indices and crevicular fluid cytokine levels: A pilot study. J Prosthodont 2006;15:108-12.

12. Yuodelis RA, Faucher R. Provisional restorations: An integrated approach to periodontics and restorative dentistry. Dent Clin North Am 1980;24:285-303.

13. John P, Anukuriakose M, Mathew JJ. The perio-restorative interrelationship- expanding the horizons in esthetic dentistry. J Interdiscip Dent 2015;5:46-53.

14. Becker CM, Kaldahl WB. Current theories of crown contour, margin placement, and pontic design. J Prosthetic Dent 2005;93:107-15.

15. Schluger S, Yuodelis RA, Page RC. Periodontal Disease. Philadelphia, PA: Lea \& Febiger; 1977. p. 586-617.

16. Orkin DA, Reddy J, Bradshaw D. The relationship of the position of crown margins to gingival health. J Prosthet Dent 1987;57:421-4.

17. Bhat VS, Prasad DK, Malli P. Periodontal prosthesis- review. NUJHS 2015;5:97-102. 